\title{
Quantitative changes in faecal microflora preceding necrotising enterocolitis in premature neonates
}

\author{
C Hoy, M R Millar, P MacKay, P G R Godwin, V Langdale, M I Levene
}

\begin{abstract}
Quantitative studies of faecal bacterial flora were carried out during the week preceding the clinical onset of 12 episodes of neonatal necrotising enterocolitis. There were considerable quantitative changes in the faecal flora preceding the clinical onset of both definite and possible episodes of necrotising enterocolitis. There was a decline in the numbers of some species from up to 72 hours before the clinical onset of the disease. Enterobacteriaceae were isolated from samples collected during the $\mathbf{4 8}$ hours preceding the clinical onset of all four definite episodes of necrotising enterocolitis. These were 'new' isolates in two episodes, and considerably increased numbers in another.

The changes that we found are probably the result of changes in intraluminal conditions that precede the clinical onset of necrotising enterocolitis.
\end{abstract}

The aetiology of neonatal necrotising enterocolitis remains unknown; its incidence rises with increasing prematurity and may reach over $13 \%$ in very low birthweight infants. ${ }^{1}$ There may be temporal and geographical clustering of cases, suggesting that a transmissible agent may play a part. $^{2}$ Previous studies of faecal flora associated with neonatal necrotising enterocolitis have concentrated on the speciation of the microbial flora present at the onset of clinical signs of disease. Clostridium $\mathrm{spp}^{34}$ enterobacteriaceae, ${ }^{5-7}$ and-most recently-coagulase negative staphylococci ${ }^{8}$ have been associated with the disease. Studies of faecal $\alpha_{1}$-antitrypsin 9 and breath hydrogen concentration, ${ }^{10}$ however, together with histological evidence (W Ballance, B Dahur, N Sheuher, R Kliegman. Proceedings of a Symposium 'Neonatal necrotising enterocolitis: current concepts and controversies'. Columbus, USA, 1989) suggest that the pathological process leading to necrotising enterocolitis may precede the onset of clinical signs of disease by hours or even days. The bacterial species present at the clinical onset therefore may not be representative of those present at the onset of the pathological process.

We describe quantitative changes in faecal microflora in the weeks preceding the onset of 12 episodes of neonatal necrotising enterocolitis.

Materials and methods

We studied the faecal flora of premature neonates with episodes of illness associated with specific signs of gastrointestinal dysfunction including abdominal distension, blood in the stools, gastric retention, abdominal wall erythema, and abnormal abdominal radiographs. Radiological abnormalities were evidence of ileus, thickening of the bowel wall, or 'rigid' loops of bowel. Episodes were divided into those associated with intramural or intrahepatic gas (definite) and those without such gas (possible).

SAMPLE COLLECTION AND STORAGE

Sample of faeces (when available) were collected by nursing staff each day from all neonates of less than 32 weeks' gestational age who had been admitted to the Peter Congdon Regional Neonatal Unit with respiratory distress syndrome between February and September 1989. Approximately $0.2 \mathrm{~g}$ of faeces was inoculated into a phial containing $1.8 \mathrm{ml}$ of prereduced glycerol citrate broth ${ }^{11}$ in an anaerobic cabinet (Wise Anaerobic Work Station, Don Whitley, Shipley). The weight of the sample was determined by subtracting the known weight of the phial from the weight after the addition of the sample. Phials containing faecal samples were stored at $-70^{\circ} \mathrm{C}$. Dry weight as a percentage of wet weight was determined after drying a weighed sample in a hot air oven for 24 hours.

\section{DETERMINATION OF QUANTITATIVE}

BACTERIOLOGY

Quantitative bacteriology was carried out within eight weeks of storage of the samples at $-70^{\circ} \mathrm{C}$. Samples were thawed at room temperature and $100 \mu$ l of the contents of the phial were serially diluted tenfold in brain heart infusion broth (Oxoid CM 225). From each dilution $100 \mu \mathrm{l}$ was inoculated onto the following solid media and incubated under the following conditions: blood agar base (Oxoid CM 55) containing 5\% horse blood incubated at $37^{\circ} \mathrm{C}$ in air; heated blood agar at $37^{\circ} \mathrm{C}$ in $5 \%$ carbon dioxide; MacConkey agar without salt (Oxoid CM $7 \mathrm{~b}$ ) at $37^{\circ} \mathrm{C}$ in air; Sabouraud's agar (Oxoid CM 41) with chloramphenicol $50 \mathrm{mg} / \mathrm{l}$ at $30^{\circ} \mathrm{C}$ in air; VCAT agar (GC agar base (Oxoid CM 367) containing 10\% lysed horse blood, GC supplement (Oxoid SR 105), vancomycin $5 \mathrm{mg} / \mathrm{l}$, colistin $6 \mathrm{mg} / \mathrm{l}$, amphotericin B $1 \mathrm{mg} / \mathrm{l}$, and trimethoprim $5 \mathrm{mg} / \mathrm{l}$ ) at $43^{\circ} \mathrm{C}$ under microaerophilic conditions; and SlanetzBartley agar (Oxoid CM 377 ) at $37^{\circ} \mathrm{C}$ in $5 \%$ carbon dioxide. The following solid media were inoculated and incubated at $37^{\circ} \mathrm{C}$ under anaerobic conditions (Wise Anaerobic Work Station): Columbia blood agar base (Oxoid CM 331) with 5\% horse blood; Rogosa's agar (Oxoid CM 627); 
Wilkins-Chalgren agar (Oxoid CM 619) with $5 \%$ horse blood, sodium pyruvate $1 \mathrm{~g} / \mathrm{l}$, and nalidixic acid $10 \mathrm{mg} / \mathrm{l}$; Veillonella agar (Difco Ltd); Columbia blood agar with kanamycin 100 $\mathrm{mg} / \mathrm{l}$ and vancomycin $7.5 \mathrm{mg} / \mathrm{l}$; and fructose agar (Clostridium difficile) (Oxoid CM 601) with $7 \%$ horse blood, cycloserine $500 \mathrm{mg} / \mathrm{l}$, and cefoxitin $16 \mathrm{mg} / \mathrm{l}$. Media incubated under anaerobic conditions were supplemented with hemin, menandione, and sodium bicarbonate. In addition, for the isolation of clostridia, $100 \mu \mathrm{l}$ of the contents of the phial were added to $100 \mu \mathrm{l}$ of $95 \%$ ethanol. ${ }^{12}$ This mixture was incubated for 30 minutes at $37^{\circ} \mathrm{C}$ before inoculation on to egg yolk agar, ${ }^{12}$ prepared with blood agar base (Oxoid CM 55), which was then incubated at $37^{\circ} \mathrm{C}$ under anaerobic conditions. All agar plates were examined for growth for up to one week after inoculation. Colonies were counted using an automated colony counter. Isolates were identified using standard laboratory methods. ${ }^{12}$

'New' isolates were defined as those strains isolated in the 48 hours preceding the clinical onset of necrotising enterocolitis but not from the samples collected in the five days before that time.

\section{Results}

A total of 752 stool samples were obtained from 90 neonates during the eight month period of the study. Seven definite episodes of necrotising enterocolitis and 11 possible episodes were diagnosed. Faecal samples were obtained during the week preceding the clinical onset of four (four babies) of the seven definite episodes and eight (seven babies) of the 11 possible episodes. The neonates who developed possible necrotising enterocolitis and from whom samples were available had a median gestational age of 27 weeks (range 26-30) and median birth weight of $995 \mathrm{~g}$ (range 660-1160). Neonates who developed definite necrotising enterocolitis and from whom samples were available had a median gestational age of 28 weeks (range 27-30) and median birth weight of $725 \mathrm{~g}$ (range 620-1440). Antibiotics were given intravenously to the babies in the week before three of the eight episodes of possible and one of the four episodes of definite necrotising enterocolitis.

All the episodes of possible and definite necrotising enterocolitis followed the introduction of nasogastric feeding (by intervals ranging from three to 16 days). In the intensive care unit there is a trend towards an increase in numbers of strains present in the faeces with time after the introduction of nasogastric feeds. A sudden decline in numbers of facultative species such as Streptococcus faecalis or Staphylococcus spp is unusual, unless it is associated with antibiotic treatment. The quantitative changes in flora before three definite episodes of necrotising enterocolitis (in three neonates) are shown in figs 1-3. Samples were available only from the $\mathbf{4 8}$ hours before the onset of the fourth definite episode of necrotising enterocolitis; a strain of Klebsiella pneumoniae was isolated at a concentration in excess of $10^{11}$ colony forming units (cfu)/g dry weight in the $\mathbf{4 8}$ hours before this fourth episode. Bacterial strains from the genus enterobacteriaceae were isolated from samples collected in the 48 hour periods before the onset of all four definite episodes of necrotising enterocolitis.
The species involved were Escherichia coli, $K$ pneumoniae (two episodes) and Enterobacter cloacae. Two of these strains were 'new' isolates (figs 1 and 3) and in a third episode (fig 2), a strain of $E$ cloacae increased considerably in concentration before the onset of necrotising enterocolitis. There
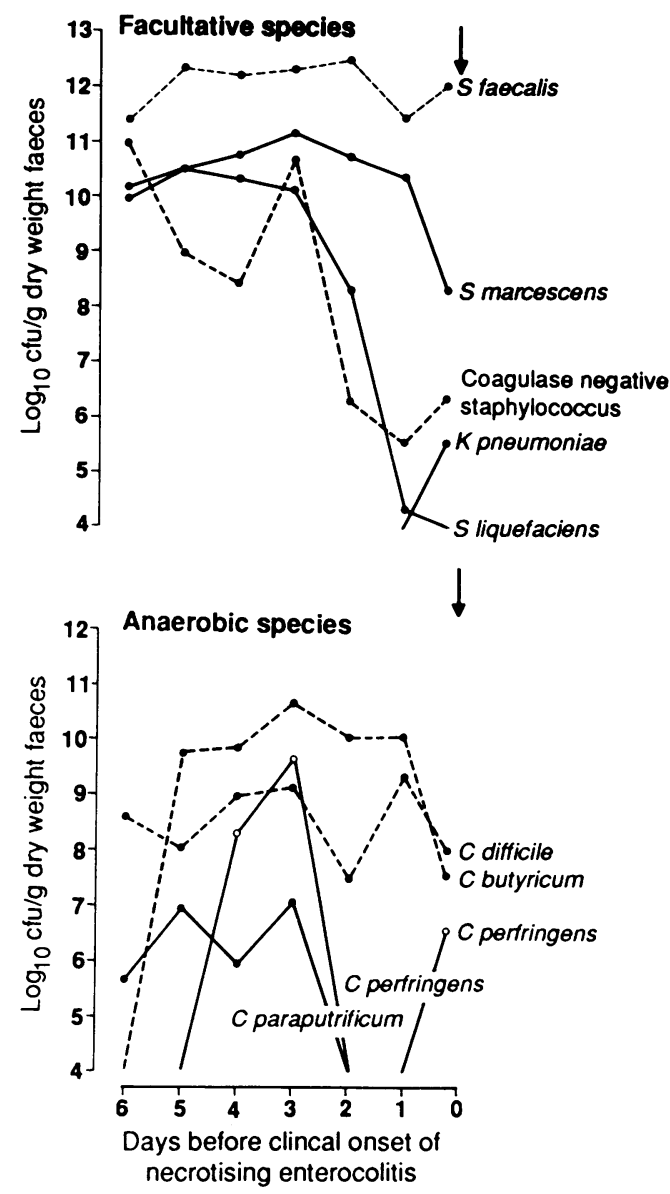

Figure 1 Changes in facultative and anaerobic species of faecal flora during the week before the clinical onset of neonatal necrotising enterocolitis.

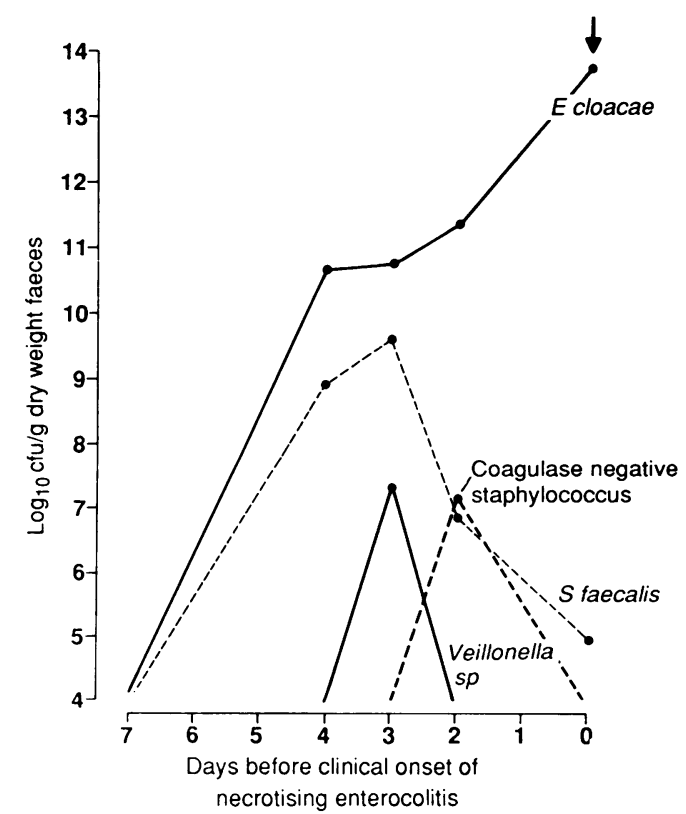

Figure 2 Changes in numbers of $E$ cloacae, $S$ faecalis, coagulase negative staphylococci, and Veillonella sp during the week before the clinical onset of neonatal necrotising enterocolitis. 


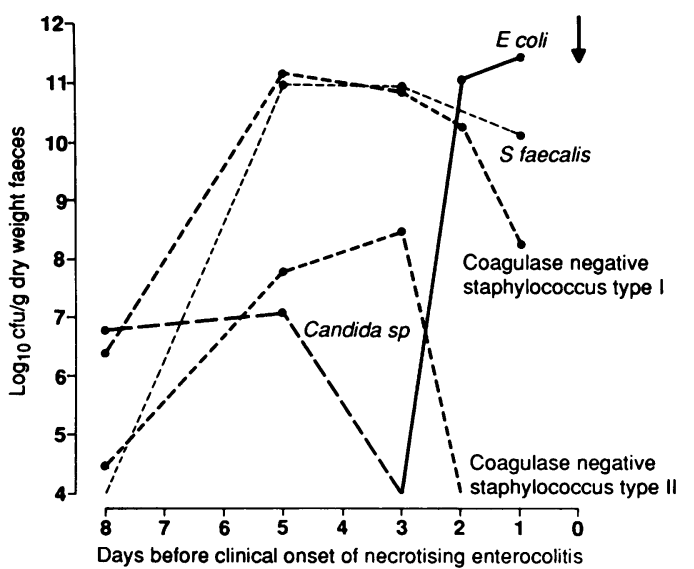

Figure 3 Changes in numbers of $E$ coli, $S$ faecalis, coagulase negative staphylococci types I and II, and Candida sp during the week before the clinical onset of neonatal necrotising enterocolitis.

was a quantitative decline in the concentration of other bacterial species including both facultative and anaerobic species from up to 72 hours before all three definite episodes of necrotising enterocolitis.

In the week before the onset of one of the definite episodes of necrotising enterocolitis (fig 1) four species of clostridia were isolated; this was an unusual pattern of colonisation. Although Clostridium spp were isolated from 19 of 121 samples (nine neonates) collected from 29 neonates admitted to the unit between six weeks before, and six weeks after, the onset of this episode of necrotising enterocolitis, in only three samples from one neonate were two species of clostridia isolated. There were no samples with three or more species.

Four of the eight possible episodes of necrotising enterocolitis were not preceded by quantitative changes (rise or fall of two or more microbial species by twice $\log _{10} \mathrm{cfu} / \mathrm{g}$ dry weight) or by the detection of 'new' isolates. 'New' isolates associated with the other four possible episodes of necrotising enterocolitis were Serratia marcescens and $S$ faecalis (episode 1); $S$ faecalis, Clostridium perfringens, and Veillonella spp (episode 2); $S$ faecalis (episode 3); and Veillonella spp, Propionibacterium spp, Candida spp, and $E$ cloacae (episode 4).

\section{Discussion}

The intramural (or intrahepatic) gas that is characteristic of necrotising enterocolitis is probably a result of bacterial fermentation of intraluminal substrates, ${ }^{13}$ and bacterial fermentation of carbohydrates in the small intestine before the clinical onset of the disease. ${ }^{10}$ Clark et al reported that mucosal lesions could be induced in the rabbit ileum by the intraluminal injection of acidified casein, and suggested that the reduction in $\mathrm{pH}$ resulting from bacterial fermentation of excess substrate within the small bowel of neonates, particularly by enterobacteriaceae that ferment lactose rapidly, ${ }^{14} 15$ may lead to similar conditions to those that induce lesions in the rabbit model of necrotising enterocolitis.

The concentration of breath hydrogen has been positively correlated with the numbers of enterobacteriaceae in the faeces of neonates. ${ }^{16}$ Previous studies have suggested a link between enterobacteriaceae and necrotising enterocolitis, ${ }^{5-7}$ 17-20 but no one species has consistently been linked with it. In this study, enterobacteriaceae were isolated from samples collected during the 48 hours before the clinical onset of all four definite episodes of necrotising enterocolitis. These were 'new' isolates in two episodes and a considerable increase in numbers in another episode. By contrast with episodes of possible necrotising enterocolitis, new isolates of other genera were not found in the $\mathbf{4 8}$ hours before the clinical onset of the definite episodes. Enterobacteriaceae were isolated from samples preceding two of the eight possible episodes of necrotising enterocolitis, and were isolated in association with 'new' isolates from other genera in those episodes. The decline in numbers of some bacterial species in the faecal flora probably resulted from alterations in substrate availability and $\mathrm{pH}$ after bacterial fermentation in the small intestine.

Bacterial fermentation in the small intestine may contribute directly to the pathogenesis of necrotising enterocolitis, ${ }^{14}{ }^{15}$ or it may result from changes in intraluminal conditions arising as a result of the disease. The changes that we have described probably result from changes in intraluminal conditions that precede the clinical onset of necrotising enterocolitis.

1 Yu VYH, Joseph R, Bajuk B, Orgill A, Astbury J. Perinatal risk factors for necrotising enterocolitis. Arch Dis Child 1984;59:430-4.

2 Book LS, Overall JC, Herbst JJ, Britt MR, Epstein B, Jung AL. Clustering of necrotizing enterocolitis: interruption by

3 Gothefors L, Blenkharn I. Clostridium butyricum and necrotising enterocolitis. Lancet 1978; $: 52-3$.

4 Han VK, Sayed H, Chance GW, Brabyn DG, Shaheed WA. An outbreak of Clostridium difficile necrotizing enterocolitis: a case for oral vancomycin therapy? Pediatrics 1983;71:935-42.

5 Speer ME, Taber LH, Yow MD, Rudolph AJ, Urteaga J, Waller S. Fulminant neonatal sepsis and necrotizing enterocolitis associated with a 'nonenteropathogenic' strain of Escherichia coli. F Pediatr 1976;89:91-5.

6 Stein H, Beck J, Solomon A, Schmaman A. Gastroenteritis with necrotising enterocolitis in premature babies. $\mathrm{Br} \mathrm{Med}$ f 1972;ii:616-9.

7 Westra-Meijer CMM, Degener JE, Dzoljic-Danilovic G, Michel MF, Mettau JW. Quantitative study of the aerobic and anaerobic faecal flora in neonatal necrotising enterocolitis. Arch Dis Child 1983;58:523-8.

8 Scheifele DW, Biornson GL. Delta toxin activity in coagulasenegative staphylococci from the bowels of neonates. 7 Clin Microbiol 1988;26:279-82.

9 Shulman RJ, Buffone G, Wise L. Enteric protein loss in necrotising enterocolitis as measured by fecal $\alpha$-1-antitrypsin excretion. $\mathcal{F}$ Pediatr 1985;107:287-9.

10 Cheu HW, Brown DR, Rowe MI. Breath hydrogen excretion as a screening test for the early diagnosis of necrotizing as a screening test for the early diagnosis of

11 Crowther JS. Transport and storage of faeces for bacteriological examination. $\mathcal{f}$ Appl Bacteriol 1971;34:477-83.

12 Lennette EM, Balows A, Hausler WJ, Shadomy HJ, eds. Manual of clinical microbiology. 4th Ed. Washington: American Society for Microbiology, 1985.

13 Engel RR, Virnig NL, Hunt CE, Levitt MD. Origin of mura gas in necrotizing enterocolitis. Pediatr Res 1973;7:292.

14 Carbonaro CA, Clark DA, Elseviers D. A bacterial pathogenicity determinant associated with necrotizing enterocolitis. Microbiol Pathogen 1988;5:427-36.

15 Clark DA, Thompson JE, Weiner LB, Schneider JA, Rofahr JE. Necrotising enterocolitis: intraluminal biochemistry in human neonates and a rabbit model. Pediatr Res 1985;19. 919-21.

16 Stevenson DK, Shahin SM, Ostrander CR, et al. Breath hydrogen in preterm infants: correlation with changes in bacterial colonization of the gastrointestinal tract. $\mathcal{F}$ Pediatr 1982;101:607-10.

17 Bell MJ, Shackelford P, Feigin RD, Ternberg JL, Brotherton $\mathrm{T}$. Epidemiologic and bacteriologic evaluation of neonatal Tecrotizing enterocolitis. F Pediatr Surg 1979;14:1-4.

18 Dellagrammaticas HD, Duerden BI, Milner RDG. Upper intestinal bacterial flora during transpyloric feeding. Arch intestinal bacterial flora

19 Frantz ID, L'Heureux P, Engel RR, Hunt CE. Necrotizing enterocolitis. F Pediatr 1975;86:259-63.

20 Stanley MD, Null DM, deLemos RA. Relationship between intestinal colonization with specific bacteria and the development of necrotizing enterocolitis. Pediatr Res 1977 11:543. 